\title{
Bedbugs Biting Back? A Multifactorial Consideration of Bedbug Resurgence
}

Vanessa L. Abejuela-Matt

Follow this and additional works at: https://aah.org/jpcrr

Part of the Community Health and Preventive Medicine Commons, and the Parasitic Diseases Commons

\section{Recommended Citation}

Abejuela-Matt VL. Bedbugs biting back? A multifactorial consideration of bedbug resurgence. J Patient Cent Res Rev. 2014;1:93-98. doi: 10.17294/2330-0698.1018

Published quarterly by Midwest-based health system Advocate Aurora Health and indexed in PubMed Central, the Journal of Patient-Centered Research and Reviews (JPCRR) is an open access, peer-reviewed medical journal focused on disseminating scholarly works devoted to improving patient-centered care practices, health outcomes, and the patient experience. 


\title{
Bedbugs Biting Back?
}

\section{A Multifactorial Consideration of Bedbug Resurgence}

\author{
Vanessa L. Abejuela-Matt, DO \\ Department of Family Medicine, Aurora St. Luke's Medical Center, Aurora Health Care, Milwaukee, WI
}

\begin{abstract}
Bedbugs, previously thought to be eradicated during the mid20th century, have reemerged in the new millennium with unforeseen furor. Affected patients and families frequently present in primary care settings, not only with complaints of pruritus or rash, but with anxiety and shame regarding the condition. Changes in eradication techniques and resistance, as well as lack of reporting - from both patients and lodging institutions - have hindered control. The increased mobility of goods and the human population has provided further avenues for bedbug spread. While current literature thoroughly describes the clinical presentation of bedbugs and the increasingly problematic effects on society, less discussed is the etiology of this comeback. This narrative review briefly describes the presentation and treatment of bedbug infestations, while focusing on the numerous and complex factors contributing to their reemergence. (J Patient-Centered Res Rev. 2014;1:93-98.)
\end{abstract}

\section{Keywords}

bedbugs, hemiptera, insects, ectoparasitic infestations

\section{Introduction}

While recent headlines have lightly played on the resurgence of bedbugs - "Bedbugs: not back by popular demand," "This really sucks," "Don't let the bedbugs bite," - there is no doubt that it is a subject heavy on the minds of the general public. ${ }^{1-3}$ From the years 2001 to 2006, the number of newspaper articles in the United States covering bedbugs more than quadrupled. ${ }^{4}$ This is not simply a media phenomenon; the pest management industry has struggled to both manage the increase in complaints, as well as the increasing time needed to eradicate infestations (Figure 1). ${ }^{5,6}$ Bedbugs have proved themselves to be a multidimensional pest, sparking both physical and mental irritation in many developing and developed countries. As public health officials struggle to temper the growth of these

Correspondence: Vanessa L. Abejuela-Matt, DO Aurora Health Center, 8348 Washington Avenue, Racine, WI 53406, Phone: 262-884-4040,

Fax: 262-884-4177, Email: vanessa.abejuela-matt@aurora.org
Figure 1. Orkin's top 50 bedbug cities in the United States in $2011 .{ }^{5}$

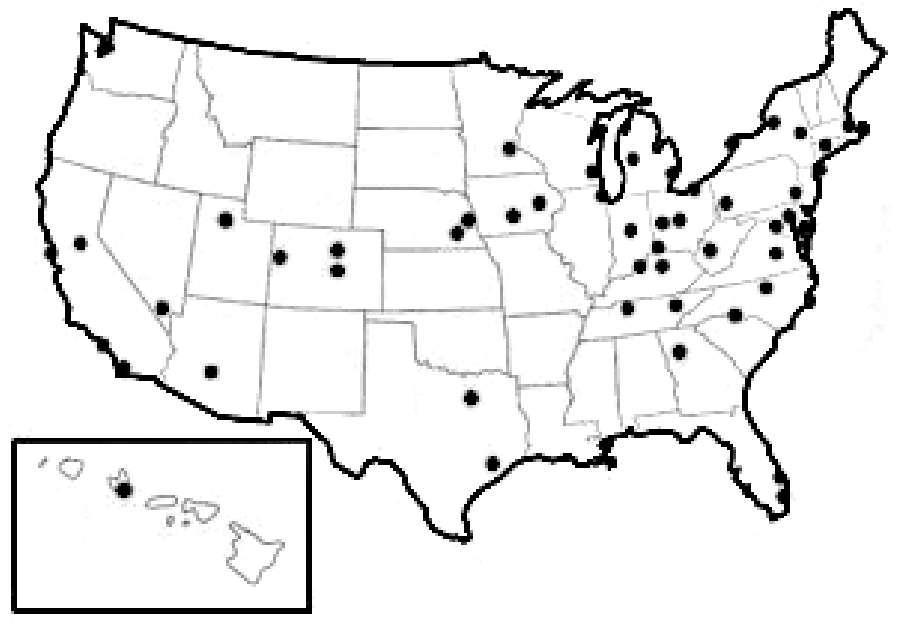

pests, the explanation for their booming resurgence from a period of relative rest and eradication starting in the $1950 \mathrm{~s}$ remains unclear. ${ }^{7,8}$

The purpose of this article is to review the current theories and potential factors involved in the worldwide resurgence of bedbug infestations. The emphasis of this article will be on the social and environmental factors, pesticide and control options, and the anatomic human and insect responses that may be contributing to the return of a pest thought to be eradicated half a century ago. ${ }^{7}$ Understanding the multifactorial etiology of this resurgence will allow for a comprehensive strategy that is emerging as an urgent necessity. Particularly, with this information, health care professionals can tailor management in the clinical setting.

\section{Epidemiology and Agent Features}

Two main species of bedbugs, from the family Cimicidae, have powered its resurgence: Cimex lectularius (of temperate origins) and Cimex heipterus (of tropical origins). ${ }^{79}$ These flightless arthropods are ovoid and flat in shape, approximately $5 \mathrm{~mm}$ long. Their blood predation is fostered by a long proboscis for sucking and saliva with vasodilatation, anticoagulation and anesthetic properties. ${ }^{8,9}$ They are attracted to human hosts at bedtime due both to warmth (thriving in temperatures that range from 7 to 45 
degrees Celcius) and the presence of carbon dioxide. ${ }^{8,10}$ They feed for 4 to 10 minutes, and can survive a year without eating. ${ }^{8,11}$ When not feeding, they nest well hidden in places with minimal light, including behind wall hangings, in mattresses and on furniture. ${ }^{8}$

\section{Clinical Presentation}

Bedbugs can cause a variety of cutaneous reactions: macules, papules, bullae, nodules and vesicles, but are classically described as wheals in clusters. ${ }^{8}$ These dermatologic fingerprints, however, can often be delayed several days or not be present at all. ${ }^{12}$ Initially, patients may complain of pruritus, which can cause human prey to relieve themselves with excoriations, which can lead to secondary infection. ${ }^{8}$ Previous sentiment had suggested that "breakfast, lunch, dinner" lesions (linear lesions of three) were pathognomonic for bedbugs, however, this is not necessarily the case as bedbugs do not always bite in clusters. ${ }^{11}$ They are attracted to areas that are exposed while sleeping, including the face, neck and extremities, but they have also been observed to feed at where clothes are held tightly against the skin (including the waistband). ${ }^{8,9}$

Diagnosis goes beyond just the appearance of bites, as consequent skin lesions are similar to a broad differential (including, but not limited to, other insect bites such as scabies, ticks and lice; food allergies; hives; drug reaction; and chicken pox). ${ }^{8,9,12}$ Additionally, the bites can often be absent of inflammatory reaction, with some victims never mounting a dermatologic response besides evidence of punctate. ${ }^{12}$ Looking for environmental evidence can reveal the bedbugs' presence. Bedbugs often leave a trail of blood drops on sheets. They also leave a distinctive musty sweet odor, detectable by trained dogs. ${ }^{10}$

\section{Treatment and Prevention}

The cutaneous reactions from bedbugs are self-limited, generally resolving within 1-2 weeks without intervention. Symptomatic treatment of pruritus or erythema includes topical antipruritic preparations containing doxepin, histamines or intermediate potency corticosteroids. ${ }^{8,9}$ Secondary infections, particularly dermatologic, are treated with topical or systemic antibiotics. Interestingly, bedbugs have been shown to be carriers of human immunodeficiency virus (HIV) and hepatitis B virus (HBV) without evidence of human transmission. ${ }^{7}$

Public health initiatives, including that of the Centers for Disease Control and Prevention and the Environmental Protection Agency, have recommended the adoption of
Integrated Pest Management, involving increasing education through collaborative efforts of the government, property managers and pest management professionals in addition to common sense practices of citizens (hygienic practices) and appropriate pest management options (pesticides, monitoring devices/traps, physical removal/vacuum, disposal). ${ }^{13}$ Common pesticides, each with variable methods of distribution, include those with pyrethroid (deltamethrin and gamma-cyhalothrin) elements, silicicates, neonicatinoids, arylpyrroles, insect growth regulators and, in some parts of the world, carbamates and organophosphates. ${ }^{7}$ Monitors and traps can include dogs sensitive to the distinctive odor as well as chemical lures and extreme temperature exposure.

\section{Methods}

A literature search was generated from the Medline database with OvidSp, using the search term "Bedbugs," limited to articles from all years and in the English language. Additionally, the references cited in these reports were reviewed to identify other sources pertinent to bedbug studies. Articles were selected for this narrative review to provide fair representation of the various current theories regarding the resurgence of bedbugs, with priority given to those articles that were recent or novel. Nonscientific articles were briefly discussed only if deemed likely to lead to scientific investigation or to persist in lay literature.

\section{Results and Discussion}

The mechanisms of the recent bedbug resurgence are multifactorial and interrelated (Figure 2). We have broadly categorized the proposed etiologies of the bedbug resurgence (Table 1). While there are many barriers to control bedbugs, numerous proposed interventions exist (Table 2).

Figure 2. Proposed mechanisms of bedbug resurgence.

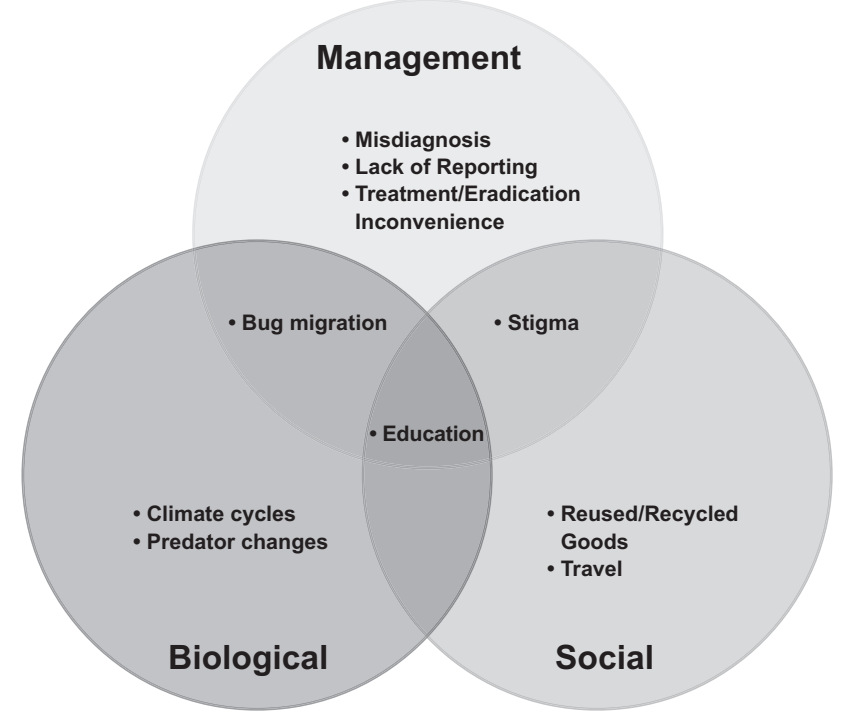


Table 1. Proposed etiologies of bedbug resurgence

\begin{tabular}{|l|l|l|}
\hline $\begin{array}{l}\text { Perception } \\
\text { never left. }\end{array}$ & $\begin{array}{l}\text { Population } \\
\text { Bedbugs have } \\
\text { increased in number. }\end{array}$ & $\begin{array}{l}\text { Resistance } \\
\text { Bedbugs are } \\
\text { surviving longer. }\end{array}$ \\
\hline $\begin{array}{l}\text { Lack of/deferred } \\
\text { surveillance }\end{array}$ & Travel & $\begin{array}{l}\text { Inadequate } \\
\text { eradication }\end{array}$ \\
\hline Misdiagnosis & $\begin{array}{l}\text { Recycled/reused } \\
\text { goods }\end{array}$ & $\begin{array}{l}\text { Environmental } \\
\text { (predators, } \\
\text { climate) changes }\end{array}$ \\
\hline Stigma & Urbanization & Genetic mutations \\
\hline
\end{tabular}

Table 2. Interventional approaches to managing bedbug resurgence

\begin{tabular}{|c|c|}
\hline $\begin{array}{l}\text { Barrier to } \\
\text { control }\end{array}$ & $\begin{array}{l}\text { Intervention } \\
\text { (example of currently practiced action) }\end{array}$ \\
\hline $\begin{array}{l}\text { Lack of/ } \\
\text { deferred } \\
\text { surveillance }\end{array}$ & $\begin{array}{l}\text { - Centralized reporting } \\
\text { www.bedbugregistry.com is a free, public } \\
\text { database of user-submitted bedbug reports } \\
\text { in the United States and Canada. }{ }^{14} \\
\text { - Mandatory reporting and surveillance, } \\
\text { similar to that for communicable diseases } \\
\text { Twenty-two states have statutes addressing } \\
\text { bedbugs, with most compelling institutions to } \\
\text { address bedbug prevention and eradication } \\
\text { but not necessarily requiring report to public } \\
\text { health departments. Texas, Kansas and } \\
\text { Arizona have mandates of report. }{ }^{15} \\
\text { - Public education to improve recognition } \\
\text { and promote reporting } \\
\text { The Centers for Disease Control and } \\
\text { Prevention and individual public health } \\
\text { departments publish information regarding } \\
\text { bedbug recognition and eradication for } \\
\text { communities. }{ }^{16,17}\end{array}$ \\
\hline $\begin{array}{l}\text { Eradication } \\
\text { resistance }\end{array}$ & $\begin{array}{l}\text { - Continuing research into and practicing } \\
\text { of successful mechanisms of eradication } \\
\text { The Environment Protection Agency (EPA) } \\
\text { and national pest management industry held } \\
\text { independent summits highlighting advances } \\
\text { in and barriers to eradication. }{ }^{8,19} \\
\text { - Adoption of effective novel or existing } \\
\text { treatments } \\
\text { The EPA recommends integrated } \\
\text { pest management as an effective and } \\
\text { environmentally sensitive approach to } \\
\text { bedbug control with a four-tiered approach of } \\
\text { setting action thresholds, identifying pests, } \\
\text { prevention, and control. }{ }^{20}\end{array}$ \\
\hline $\begin{array}{l}\text { Increased } \\
\text { mobility }\end{array}$ & $\begin{array}{l}\text { - Increased awareness of modes of } \\
\text { transmission } \\
\text { Various public health initiatives in public } \\
\text { education have addressed modes of } \\
\text { transmission to help communities prevent } \\
\text { spread. }{ }^{16,17}\end{array}$ \\
\hline
\end{tabular}

\section{Treatment and Prevention}

Ineffectiveness of current pesticides and monitoring practices: Public health organizations have acknowledged that there is limited public awareness, both in the private and government sectors, to the degree of infestation as well as the symptoms, treatment and prevention of infestations. ${ }^{21} \mathrm{~A}$ bedbug infestation, despite its communicable nature, is not a reportable disease. Thus, not only is it difficult to prevent its spread, but tracking and validating it can be elusive. ${ }^{4,22}$ It could be suggested that this lack of reporting may have contributed to the previous perceptions of complete bedbug eradication.

Further delaying eradication are the limited resources of public health departments. Bedbugs are frequently not seen as a high priority. ${ }^{13}$ While the responsibility for addressing infestations does not fall solely on public health departments, it is unclear who is ultimately responsible. Municipal codes do not dictate whether tenants or landlords are liable for the costs of management. ${ }^{13}$

While there are a variety of methods to meeting the challenge of infestations, many are costly in both time and money. ${ }^{7}$ Eradication can be cost-prohibitive to affected consumers, with a one-bedroom treatment costing between $\$ 800$ and $\$ 1,200 .^{23,24}$ Given that many pesticides require repeat or prolonged exposure, some households may shorten the course due to either expense or improper education about duration of treatment. ${ }^{6}$ One could speculate that those unfamiliar with the necessary principles of effective bedbug treatment may have these misconceptions and allow infestations to wax and wane, without early or complete eradication.

Additionally, some makers of pesticide products have designed products, which focus on convenience as opposed to efficacy. Multiple bug bombs, or foggers, which disperse aerosolized pesticide, without full fumigation, have been shown to be ineffective in penetrating the hidden caverns of bedbugs. ${ }^{7,25}$ In fact, sublethal levels of exposure may actually inspire the insects to more activity. ${ }^{26}$ Fumigation, aerosolized and dust formulations generally remain effective options, and are often more effective than liquid forms when used with appropriate pesticide. ${ }^{7}$

The demand for pest management has multiplied in recent years. However, the number of pest management workers has not kept pace with the growth of bedbug infestations. Given that the mode of detection is dependent on visual inspection, it can be speculated that efficacy is operator-dependent. Particularly, canines have been quite effective in detection with up to $98 \%$ accuracy. ${ }^{27}$ However, in 2009, only 100 trained dogs existed 
in the United States and this method of detection, like most other forms of bedbug control, is quite costly. ${ }^{7,28,29}$ Canine surveillance is simply for detection; chemical or mechanical eradication techniques are still necessary.

Biological pest control is not a viable option, as the main predator of bedbugs, Reduvius personatus - commonly known as the masked hunter - can cause very painful bites, comparable to bee stings. Other predators of the bedbug include arthropods of the following families: Blattaria (cockroaches) and Formicidae (ants). Other predatory insects are of the orders/classes: Hemoptera (other true bugs like bedbugs), Araneaea (spiders, particularly Thanatus flavidu), and Pseudoscorponida (pseudoscorpions). ${ }^{30,31}$ However, many of these potential predators, particularly cockroaches and ants, are associated with similarly intolerable effects and risks. ${ }^{32,33}$ Additionally, none of these have been used to successively control bedbug infestations. ${ }^{30}$

Ban of effective pesticides, predator changes: As previously discussed, the natural enemies of bedbugs are masked hunter bugs, cockroaches, ants, pseudoscorpions and spiders. Many insects during the period of extensive bedbug eradication (the first half of the 20th century) were also susceptible to the extensive and effective use of the pesticide dichlorodiphenyltrichloroethane (DDT). ${ }^{34,35}$ Initially this chemical was used to prevent vector transmission of illness, but use then shifted to promote crop production. Widespread application was used prior to the 1972 American ban of DDT, which was due to environmental and human endangerment. ${ }^{10}$ While some insects developed resistance, many experienced varying degrees of eradication, including those predators of bedbugs. ${ }^{35}$

One could speculate that this potential natural predator population depression may have been maintained or accentuated with the increased use and development of other pesticides, particularly common household insecticides. Total expenditures on all forms of pesticides, herbicides and fungicides, used in both the agricultural and commercial sectors, in the United States had increased by $70 \%$ from 1988 to $2007 .{ }^{36}$ In 2007 alone, 78 million homes were using any form of pesticide. This figure does not delineate what portion of this practice accounts for the likely increased purchase of pesticides targeting bedbugs.

Misdiagnosis by medical providers: Bedbug effects on the human integument vary widely. Given the broad differential, diagnosis and treatment are often subject to trial and error. Recurrence of alleviated or resolved symptoms may be presumed to be manifestations of chronic conditions, such as eczema or allergies. ${ }^{12}$ Symptomatic relief may be sufficiently acceptable for both patients and their caretakers, particularly if visualization of the agent is not noted. Reliance on symptomatic relief only may lead to continued presence and proliferation of bedbugs in homes where a thorough pesticide treatment has yet to occur.

\section{Genetic}

Multistrain mutation vs. single-source superbug: As previously mentioned, it is clear that current bedbugs express variable susceptibility to available and commonly used pesticides, particularly pyrethroids. ${ }^{34}$ While it was theorized that a "super bedbug" had emerged from mutation and was proliferating, leading to widespread resistance, it is more likely that there are multiple groups of resistant populations. High genetic diversity has been demonstrated across all infestations in a selection of representative Eastern U.S. populations. ${ }^{37}$ However, within contained infestations, low genetic diversity is observed. From this, it has been proposed that multiple introductions of propagules are responsible for the diversity of alleles responsible for resistance.

Multiple means of resistance to pesticides have been noted in single population studies of bedbugs. It is suspected that the general mechanism of resistance involves increased metabolism and detoxification of pesticides. ${ }^{38}$ Several cytochrome P450 and carboxylesterase, enzymes of metabolism and genes, in addition to point mutations in subunits of voltage-gated sodium channels, have been proposed to give bedbugs their penchant for survival despite chemical eradication attempts. ${ }^{6,34,39}$

\section{Social}

Travel: Increased mobility has been an achievement of modern society, with ready accessibility to vehicles and flight for both intercontinental business and pleasure purposes. As previously discussed, it is likely that pesticide resistance was obtained from bedbugs previously limited to non-American landscapes, which were then transported to the United States. ${ }^{6}$ However, it is also likely that increased bedbug dispersion has also resulted from domestic migration, including city-to-city and home-to-home travel. ${ }^{40}$ This is not just from hitchhiking bugs on humans and their belongings, but humans visiting high-traffic areas (i.e. hotels, airports) where bugs permanently nest. ${ }^{7,40,41}$ Demonstrating this, news report trends from 2001 to 2008 revealed bedbug articles that follow the proliferation, which initially began in East Coast hubs of travel, particularly New York City, with gradual increases in articles on the South and West regions. ${ }^{4}$ 
Reuse and recycling of goods: The increased exchange of second-hand furniture has been proposed as an amplified mode of passive dispersal for bedbugs. ${ }^{29}$ Given their propensity for wall hangings and furniture, it can be supposed that the general population's growing interest in finding distinctive pieces, minimizing environmental imprint, and facing economic depression has provided a new route of transmission with efficient traffic for these predators. ${ }^{9}$ The average thrift shop sales increase for the month of October in 2008 , compared to the previous year, was $35 \%{ }^{42}$

Interestingly, although there has been a surge in sales, organizations like the Salvation Army have reported a decline in donations as goods have a longer shelf life than in previous decades. Applying this to the public, it can be hypothesized that infested furniture could be retained for their enduring quality if owners are not suspecting pest penetration. Notorious for infestation, some hotels had previously sold refurbished mattresses to their peers in the industry, as well as the common citizen, propagating the spread of bedbugs. ${ }^{43}$

Past underreporting and stigmatization: Another possibility that has been raised is that the reported eradication of bedbugs in midcentury industrialized nations did not actually occur to the extent presumed. Rather, underreporting and demagnification of this occurrence was adopted for various reasons. The stigma of bedbugs on patients is well documented, leading to anxiety and shame, and hesitation to report. ${ }^{4,12}$ One might imagine that patients would be hesitant to admit to a condition linked to poor socioeconomic status and hygiene, not only to their caretakers, but also those in their social circles. ${ }^{7}$ In this manner, social stigma may likely contribute to undertreatment.

Additionally, with the dynamic historical changes of society, media reporting has naturally swayed to sensational topics. For example, news outlets in New York City initially reported informative blurbs in regard to bedbugs during the years preceding the Sept. 11, 2001, attacks. ${ }^{4}$ As recovery progressed in later years, news reporting of bedbugs trended more to reports of bedbug infestation incidents. Similarly, the public health and medical industry has tended to focus on novel or health conditions with more serious consequences, such as pregnancy or infectious disease..$^{13}$ It can be speculated that this may have limited the attention committed to bedbugs.

\section{Environmental}

Climate cycles: Average surface temperatures in the contiguous United States have increased by an average of
1.3 degrees Celsius over the last 100 years. ${ }^{44}$ This warmer environment may be more suitable for bedbugs, which thrive in temperatures between 28 and 32 degrees Celsius. ${ }^{45}$ A suspected factor in global warming - the increased production of carbon dioxide from industrial sources is also an attractant of bedbugs. ${ }^{9,44}$ With growing global industrialization, some lay media sites theorize that bedbugs are finding more and more desirable habitats and the human prey they seek..$^{13,46}$

Urbanization: Global industrialization has led to a proliferation of urbanized areas. ${ }^{4}$ Not only are these hightraffic areas, but potential habitats for bedbugs lie in close proximity (i.e. apartment buildings). ${ }^{40}$ As previously mentioned, bedbugs can travel via routes provided by human belongings, but the proximity allowed by urbanization also affords them ability to easily travel without assistance.

\section{Conclusion}

It is clear that bedbugs are resurging as a major pest, not limited to just highly populated transit centers of the United States. While increase in world travel was thought to be a major player in what brought bedbugs back, as a public health concern, it is clear that the resurgence has a multifactorial etiology. Social, environmental and genetic factors all have played a part in giving power to the growing infestations of bedbugs, while resistance to pesticides and lack of education regarding treatments and prevention have allowed the bedbug to maintain survival. As public health officials advocate for greater awareness in the public and private sectors, it has become clear that success in eradication is no longer just a chemical treatment of symptoms and infestation. Rather, residents, government and public health bodies, housing officials and medical practitioners must work together to comprehensively address the multiple causes of this resurgence of a pest that most likely never left. For those regulating and housing bodies, this involves developing policies regulating standards of reporting and eradication. For those in clinical practice, recognizing symptoms and developing standard recommendations for patient eradication will be key to keeping these pests at bay. It is hoped that this information affords the clinician ready answers for an inquisitive patient asking, "Why are bedbugs back?"

\section{Acknowledgments}

The author wishes to thank Dennis J. Baumgardner, MD, for guidance and inspiration in preparing this manuscript. Also, thank you to Kathy Strube and Lucy Webb for their library assistance.

\section{Conflicts of Interest}

None 


\section{References}

1. Hurst S, Humphreys M. Bed bugs: not back by popular demand. Dimens Crit Care Nurs. 2011;30:94-6.

2. Von Druehle D. This really sucks. Time. 2010;176:36-8.

3. Sutton T, Thomas DJ. Don't let the bed bugs bite. Nursing. 2008;38:24.

4. Anderson A, Leffler K. Bed bug infestations in the news: a picture of an emerging public health problem in the United States. $J$ Environ Health. 2008;70:24-7.

5. Orkin's Top 50 Bed Bug Cities. Orkin Pest Control website. http:// www.orkin.com/press-room/several-spring-break-destinations-onorkins-top-50-bed-bug-cities-list. Accessed June 13, 2013.

6. Gangloff-Kaufmann J, Hollingsworth C, Hahn J, Hansen L, Kard B, Waldvogel M. Bed bugs in America: a pest management industry survey. Am Entomol. 2006;52:105-6.

7. Doggett S, Dwyer D, Penas P, et al. Bed bugs: clinical relevance and control options. Clin Microbiol Rev. 2012;25:164-92.

8. Studdiford J, Conniff K, Trayes K, et al. Bed bug infestation. Am Fam Physician. 2012:86:653-8.

9. Criado P, Belda Junior W, Criado R, Silva R, Vasconcelos C. Bed bugs (Cimicidae infestation): the worldwide renaissance of an old partner of human kind. Braz J Infect Dis. 2011;15:74-80.

10. Lavery MJ, Parish LC. Bed bugs revisited. SKINmed. 2011;9:6-8.

11. Parish LC, Wikowski JA. The bed bugs never left. SKINmed. 2004;3:69-70.

12. Doggett S, Russel R. Bed bugs: what the GP needs to know. Aust Fam Physician. 2009;38:880-4.

13. Rossi L, Jennings S. Bed bugs: a public health problem in need of a collaborative solution. J Environ Health. 2010;72:34-5.

14. The bed bug registry. The Bed Bug Registry website. www.bed bugregistry.com. Accessed June 13, 2013.

15. State bed bug laws. The National Conference of State Legislatures website. http://www.ncsl.org/issues-research/env-res/state-bed buglaws.aspx. Accessed June 13, 2013.

16. Bed bug information. The City of Chicago's Official Website. http:// www.cityofchicago.org/city/en/depts/bacp/supp_info/bed_bug_ information.html. Accessed April 24, 2013.

17. Parasites-bed bugs. Centers for Disease Control and Prevention website. http://www.cdc.gov/parasites/bed bugs/. Accessed June 13, 2013.

18. Feldlaufer, M. Researching Bed Bugs: What's Known and What's Next. Proceedings of National Bed Bug Summit. 2009 April 14-15; Arlington, VA, USA. http://www.epa.gov/oppfead1/cb/ppdc/bed bug-summit/22-whatknown.pdf. Accessed June 13, 2013.

19. Global bed bug summit. Bed Bug Central website. http://www.bed bugcentral.com/summit/. Accessed June 13, 2013.

20. Integrated pest management (IPM) principles, pesticides: topical and chemical fact sheets. Environmental Protection Agency website. http://www.epa.gov/pesticides/factsheets/ipm.htm. Accessed June 13, 2013.

21. Centers for Disease Control and Prevention. Joint statement on bed bug control in the United States from the U.S. Centers for Disease Control and Prevention (CDC) and the U.S. Environmental Protection Agency (EPA). Atlanta: U.S. Department of Health and Human Services; 2010. http://www.cdc.gov/nceh/ehs/publications/ bed_bugs_cdc-epa_statement.htm. Accessed June 13, 2013.

22. Furlow, B. Spotting bed bug bites in primary care. Proceedings of the American Academy of Nurse Practitioners. 2011 Conference; 2011 June 25; Las Vegas, USA: The Clinical Advisor, 2011. http:// www.clinicaladvisor.com/spotting-bed-bug-bites-in-primary-care/ article/206143/. Accessed June 13, 2013.

23. Bruno L. A real nightmare: bed bugs biting all over U.S. MSNBC. 2010 June 27. http://www.nbcnews.com/id/38382427/ns/healthhealth_care/t/real-nightmare-bed-bugs-biting-all-over-us/\#. UXdfAytNQ9o. Accessed January 10, 2011.

24. Wang C, Tsai W, Cooper R, White J. Effectiveness of bed bug monitors for detecting and trapping bed bugs in apartments. J Med Entomol. 2011;104:275-9.
25. Jones S, Bryant J. Ineffectiveness of over-the-counter total-release foggers against the bed bug (Heteroptera: Cimicidae). J Econ Entomol. 2012;105:957-63.

26. Romero A, Potter M, Haynes K. Behavior responses of the bed bug to insecticide residues. J Med Entomol. 2009;46:51-7.

27. Pfiester M, Koeler P, Pereira R. Ability of bed-bug detecting canines to locate live bed bugs and viable bed bug eggs. J Econ Entomol. 2008;101:1389-96.

28. Juliano, M. Dogs don't let the bed bugs bite. Stamford Advocate. 2009 September 1. http://www.stamfordadvocate.com/news/article/ Dogs-don-t-let-the-bed-bugs-bite-6541.php. Accessed November 1, 2012.

29. Wilson K. They only come out at night: bed bugs and their alarming resurgence. Nursing. 2011;41:45-8.

30. Krinsky WL. True bugs (Hemiptera). In: Mullen GR, Durden LA (eds). Medical and Veterinary Entomology, Second edition. Burlington: Elsevier; 2009.

31. Forattini O. The Cimicideos and its public health importance (hemiptera-Heteroptera, Cimicidae). Rev Saude Publ. 1990;24:1-37.

32. Vaickus L, Bouchard J, Kim J, Natarajan S, Remick D. Cockroach allergens induce biphasic asthma-like pulmonary inflammation in outbred mice. J Asthma. 2012;49:510-21.

33. Habif TP. Infestations and bites. In: Habif TP (ed). Clinical Dermatology, Fifth Edition. Mosby Elsevier; 2010, pp. 581-634.

34. Adelman Z, Kilcullen K, Koganemaru R, Anderson M, Anderson T, Miller D. Deep sequencing of pythroid-resistant bed bugs reveals multiple mechanisms of resistance within a single population. PLoS One. 2011;6:e25228.

35. Ter Poorten M, Prose N. The return of the common bed bug. Pediatr Dermatol. 2005;22:183-7.

36. 2006-2007 Pesticide market estimates. United States Environmental Protection Agency website. http://www.epa.gov/pesticides/pestsales/ 07pestsales/table_of_contents2007.htm. Accessed April 23, 2013.

37. Saenz V, Booth W, Schal C, Vargo E. Genetic analysis of bed bug populations reveals small propagule size within individual infestations, but high genetic diversity across infestations from the eastern United States. J Med Entomol. 2012;49:865-75.

38. Zhu F, Sams S, Moural T, Haynes KF, Potter MF, Palli SR. RNA interference of NADPH-Chytochrome P450 reductase results in reduced insecticide resistance in the bed bug, Cimex lectularius. PLoS One. 2012;7:e31037.

39. Zhu F, Wigginton J, Romero A, et al. Widespread distribution of knockdown resistance mutations in the bed bug, Cimex lectularis (Hemiptera: Cimicidae), populations in the United States. Arch Insect Biochem. 2010:73:245-57.

40. Delaunay P. Human travel and traveling bed bugs. J Travel Med. 2012;19:373-9.

41. Bernardeschi C, Cleach L, Delaunay P, Cosidow O. Bed bug infestation. BMJ. 2013;346:f138.

42. Associated Press. While economy dives, thrift shops thrive. NBC News. 2008 October 7. http://www.today.com/id/27070237/ns/ today-today_news/t/while-economy-dives-thrift-shops-thrive/\#. UXiJtitNQ9o. Accessed April 24, 2013.

43. Kells S. Bed bugs: a systemic pest within society. Am Entomol. 2006;52:107-8.

44. Environmental Protection Agency. Climate change indicators in the United States. Environmental Protection Agency website. http://www. epa.gov/pesticides/pestsales/07pestsales/table_of_contents2007. htm. Accessed April 23, 2013.

45. Harlan H. Bed Bugs 101: the basics of Cimex lectularius. Am Entomol. 2006;52:99-101.

46. Discovery News. Bug outbreaks mostly not due to warming. 2013 February 11. http://news.discovery.com/earth/bug-infestationsspiders-bed bugs.htm. Accessed April 24, 2013.

(C) 2014 Aurora Health Care, Inc. 